\title{
Lecture Time Table Reminder System on Android Platform (Case Study: Final Year Students, Computer Science Department)
}

\author{
${ }^{1}$ Ayeni Olaniyi Abiodun, ${ }^{2}$ Dada Olabisi, ${ }^{3}$ Talabi Olanrewaju \\ ${ }^{1}$ Federal University of Technology, Akure, Ondo-State, Nigeria \\ ${ }^{2}$ Kwara State Polytechnic, Ilorin, Kwara-State, Nigeria \\ ${ }^{3}$ Federal University of Technology, Akure, Ondo-State, Nigeria
}

\begin{abstract}
Forgetting the stipulated schedule or time of lectures due to one reason or the other has always been a major concern for students resulting in the students missing classes and thereby lagging behind in what the lecturer has taught the other students. The main purpose of developing the Lecture time table reminder system is to minimize this problem to an acceptable level. Lecture Timetable Reminder System is a mobile application developed on the Android platform for the students of Computer Science, 500level, Federal University of Technology, Akure, with the service of reminding them about their lectures. The major tools used in developing this application are Java, Eclipse, Android Software Development Kit (SDK), PHP and MySQL. Java is the programming language that was used and Eclipse is the Integrated Development Environment (IDE) and Android SDK is a virtual device emulator. Then PHP was used to produce a response customized for each user's request to the application, MySQL is the database.
\end{abstract}

Index Terms: Reminder, lecture, time-table, android phones, system

(C) 2017 Published by MECS Publisher. Selection and/or peer review under responsibility of the Research Association of Modern Education and Computer Science

\section{Introduction}

Reminder is a tool that lets you keep track of all the things you need to know like due dates and locations. Reminder has turned to be a very important tool in time management. And it is a common saying in time management that it is better to keep track of things using a system rather than your memory.

A Reminder System is important for busy people because we do not have to remember all our works. And writing them down somewhere is not a very good idea because then we have to keep track of that piece of paper. The Reminder System lets you "set and forget" and then get reminded when the time comes. And so it

* Corresponding author.

E-mail address: olaniyiayeni17@gmail.com,mrsdadaolabisim@yahoo.com, larrsonbaba.benjamin107@gmail.com 
becomes a perfect tool for business or personal follow up.

According to Wikipedia, Android platform is a mobile operating system based on the Linux kernel and currently developed by Google. With a user interface based on direct manipulation, Android is designed primarily for touchscreen mobile devices such as smartphones and tablet computers.

Modern mobile devices such as smartphones have become increasingly powerful and also part of day-to-day lives of the people. As mobile devices become more like PCs they will come to replace objects we tend to carry around such as planners, to do list etc. and also help in accomplishing our daily tasks. (Divya et al, 2012)

The increasing growing in the popularity of the android devices is part of the few reasons I decided to choose this platform for the implementation of this project. Lecture time table reminder system is an application which is meant to prevent users (both students and lecturers) from being forgetful about the lecture they have according to the information they have entered.

\section{Tools Needed}

Tools needed in designing and implementing the project are as follows:

1. Java: This is the major programming language that will be used to implement this project. This is chosen due to the fact that it is an object oriented program which will make each and every entities or objects involved to be well represented.

2. PHP (Hypertext Pre-Processor): This is a server-side scripting language designed specifically for the Web. This particular tool will be needed because there will be some part of the application that will be needed to connect to the web.

3. Structured Query Language (SQL): This is a language specifically designed with databases in mind. SQL is the database tool that will be used for this project because there is need for a database, adding of new data, maintaining data and also retrieve selected parts of the project.

4. Android phone for testing of the application.

5. Graphical User Interface (GUI): This is interacting point between the user and the application. Lectures timetable will be inputted into the application through this.

6. Android Software Development Kit (SDK): It includes a mobile device emulator, a virtual device emulator that runs directly on computer. With the help of this emulator the application will be prototyped, developed and tested without having a physical device (when one was not available).

7. Eclipse: Eclipse will be used for development because; it is a multi-language software development environment comprising a base workspace and an extensible plug-in system for customizing the environment.

Java is the programming language that will be used and Eclipse is the Integrated Development Environment (IDE) where the java code will be typed and compiled and Android SDK is a virtual device emulator that runs directly on the computer and will enable us to see how the program will actually work even without a physical device. Then PHP will be used to produce a response customized for each user's request to the application, SQL is the database where data inputted by the users will be stored, and from which response will be pulled from according to the request of the user.

\section{System Analysis and Design}

This section describes the system design, input, output and processing requirements of the proposed system and the hierarchical design of the proposed system. It also describes/defines different components that make up the system, how they are connected together, what the system does and how it operates. 


\section{A. System Architecture}

The system architecture illustrates the database of the time table being loaded into the webserver and the webserver loading or downloading the timetable into the android phone of the user (the user must have downloaded the application and signed up at the first use of the application). Below is the system architecture of the lecture time table reminder system on the android platform.

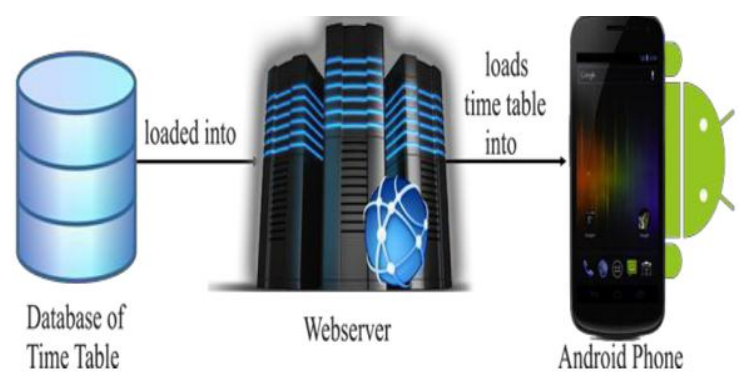

Fig.1. System architecture

The application was developed through several steps as shown in the figure below. The steps comprises of all the design and development efforts that was carried out. The following sections describe each step in detail:

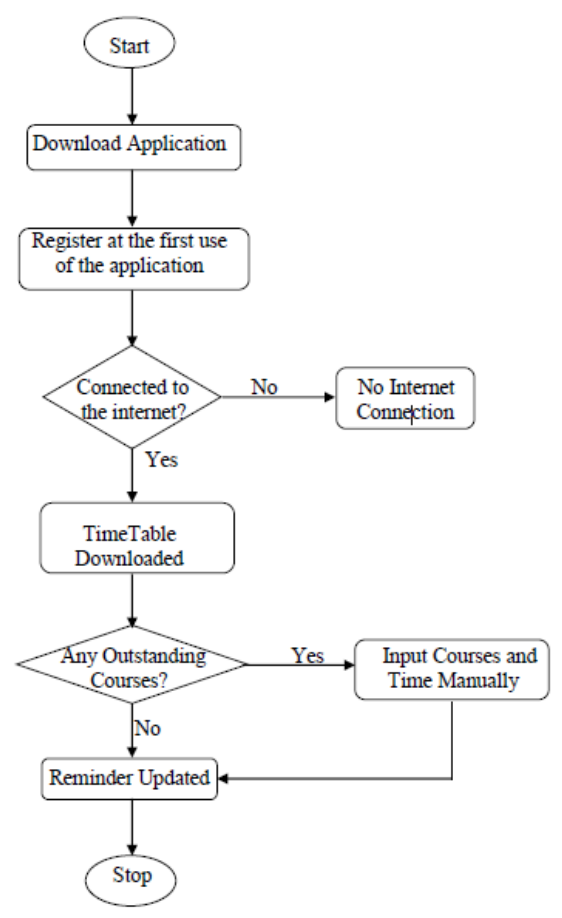

Fig.2. Flowchart of the lecture reminder 
In the first step, the user will need to download the application on his/her android phone before he/she will be able to explore the timetable reminder. After which the user will register at the first use of the application and the user must be connected to the internet at least for the first use of the application after which he/she will no longer to be connected to the internet to use the application. The third step has two values, true or false. In the true case, the application downloads the preloaded timetable and this makes the reminder to be eligible for the next procedure. While in the false case, the application brings out an error message that displays that there is no internet connection. The next step also has two values, true or false. In the false case, the reminder is updated while in the true case, the application prompts the user to enter his/her courses and the time stipulated for those courses and then moves on to get the reminder updated.
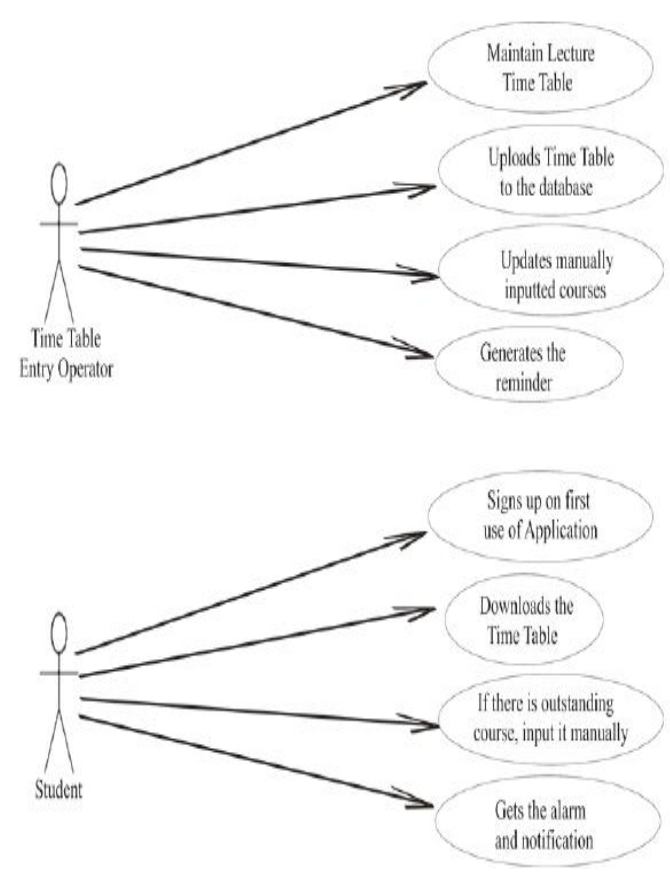

Fig.3. Use case diagram

\section{Implementation and Testing}

This section introduces the full documentation of the designed lecture reminder system. The hardware and software specifications of the system used in developing the application are stated here. Also, the specifications of the android phone used in testing the lecture time table reminder system are also highlighted.

\section{A. Specifications of the Computer System Used}

The specifications of the computer system used in developing the reminder system are grouped into two, which are hardware specifications and software specifications.

\section{B. Hardware Specifications}


The following are the hardware specifications of the computer system:

a. Processor speed: $2.20 \mathrm{GHz}$

b. RAM: 4GB

c. Hard disk size: $640 \mathrm{~GB}$

\section{Software Specifications}

The following are the software specifications of the computer system:

a. Operating System: Windows 8.1 pro, 64-bit

b. Eclipse with Android SDK

D. Specifications of the Android Phone Used in Testing

Listed below are the specifications of the android phone that was used in the testing of the lecture time table reminder system:

a. Name of device: Tecno

b. Model: N9

c. Android Version: 4.2.1

d.Baseband Version: MOLY.WR8.W1248.md.wg.mp.v8.p8, 2013/08/12 13:34

e. Kernel Version: 3.4.5

f. Build Number: N9_A2000_20130813_V0_1_9

g. Internet connection for the first use of the application only

\section{E. Requirements of Android Phone Needed to Run the Application}

To be able to run the lecture timetable reminder system effectively, the following are the basic requirements the phone needs:

a. Operating System: Android

b. Kernel Version: from 17 to 21

c. Operating System Version: 4.2 and higher. It can also work for android version lower than 4.2 due to downward compatibility.

d. Internal Memory: the application is of $1.15 \mathrm{MB}$ size after installation and so, will need at least $3 \mathrm{MB}$ of the internal memory

\section{Implementation with Result}

The following figures are the different screens of the lecture time table reminder application and the description of the action they perform are given along with them.

At launching the application, below is the image of the home screen of the application where the user signs up at the first use of the application. At this point, the android device must be connected to the internet so as to be able to download the time table from the database to the device. 


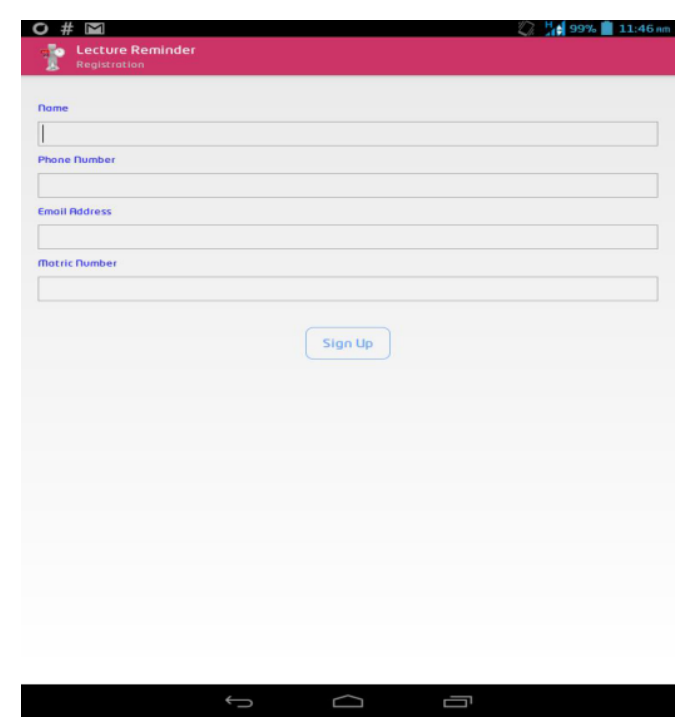

Fig.4. Home page

The next screenshot is that of the user entering his/her details to the signup page. As seen in the screenshot, the details that are needed are: name, phone number, email address, and matric number. After entering all these details, the user clicks on the "sign up" button and that takes the application to the next phase

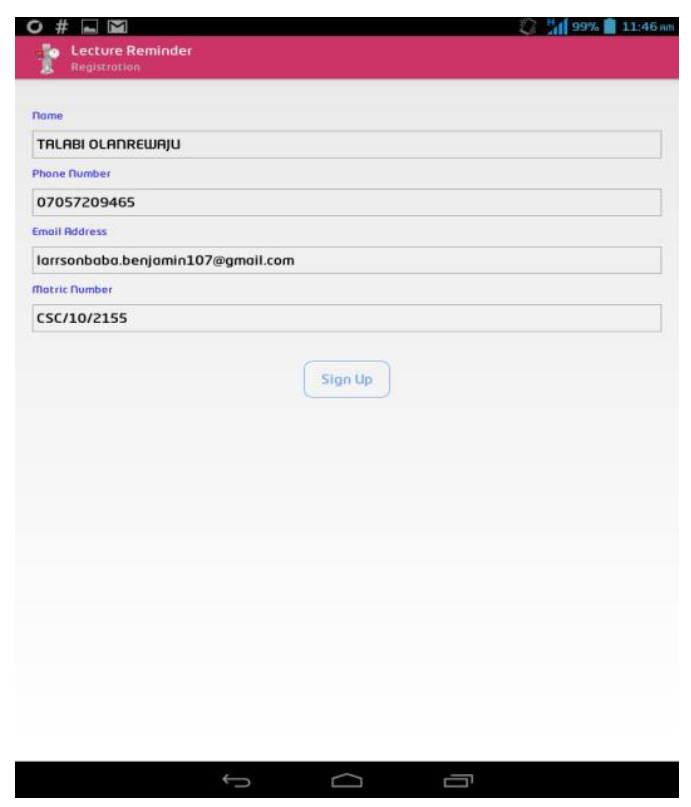

Fig.5. Sign up page

The next screenshot is that of the page where you click on the "load application" button which triggers the downloading of the time table from the database online to the data of the reminder application. The timetable 
that will be downloaded will include only compulsory courses that every Computer Science 500level students must offer

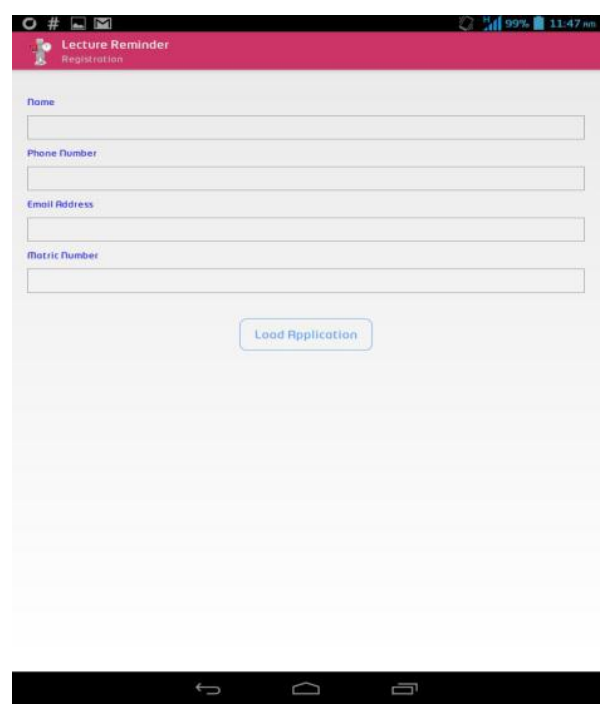

Fig.6. Application loading page

The next screenshot shows how the application looks when it is loading the lecture timetable into android device. After the time table has been successfully loaded, there is a notification that shows that the timetable has loaded successfully

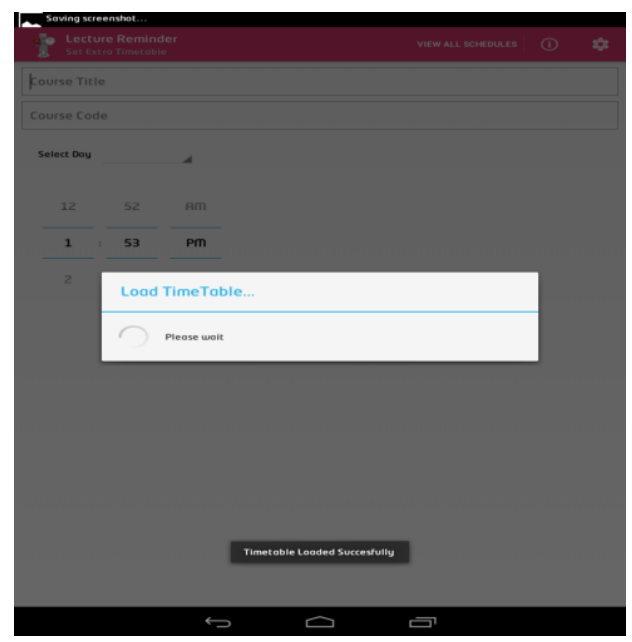

Fig.7. Time-table loading in progress

The next screenshot shows the page where the user entered his/her outstanding course by entering/inputting the course title, the course code, the day of the lecture, and the time of the lecture. After entering all the details 
of the courses, the user clicks on the "save" button. After clicking the "save" button, there is a notification that displays that the schedule has been saved

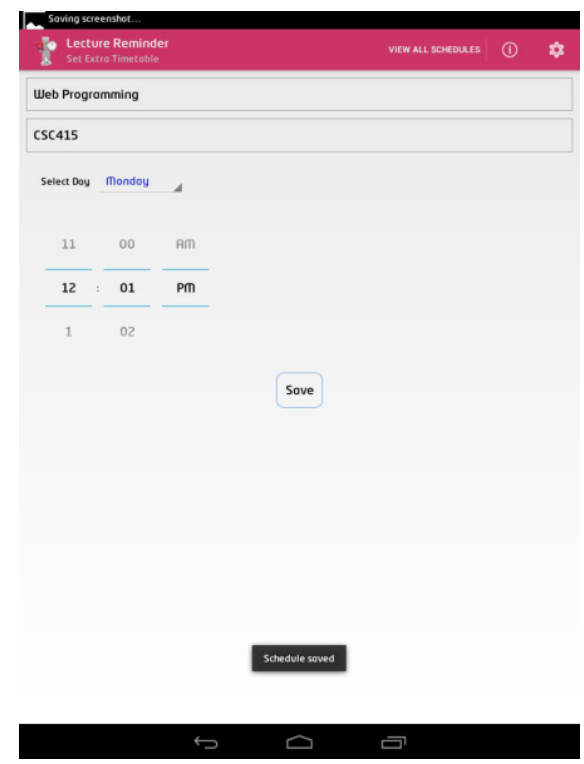

Fig.8. Outstanding courses inputted \& saved

To view the preloaded lecture timetables or even the manually inputted courses, you click on the "view all schedules" button on the top right corner of the application and this displays all the compulsory courses and the outstanding course(s) that has been inputted manually. Below is the screenshot that shows the "view all schedules" page.

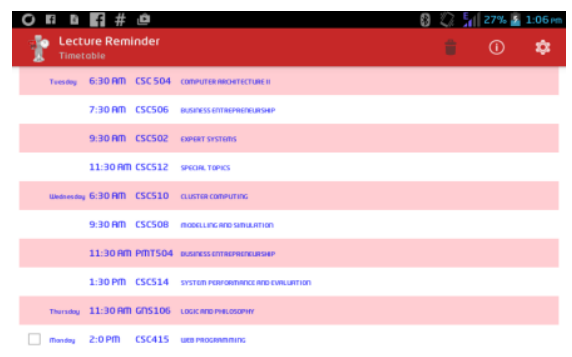

Fig.9. Course scheduling page 
Below is the screenshot of the settings that needs to be done in the application which includes choosing the notification sound. This page can be gotten to by clicking on the settings icon beside the information icon on the manual input page of the application

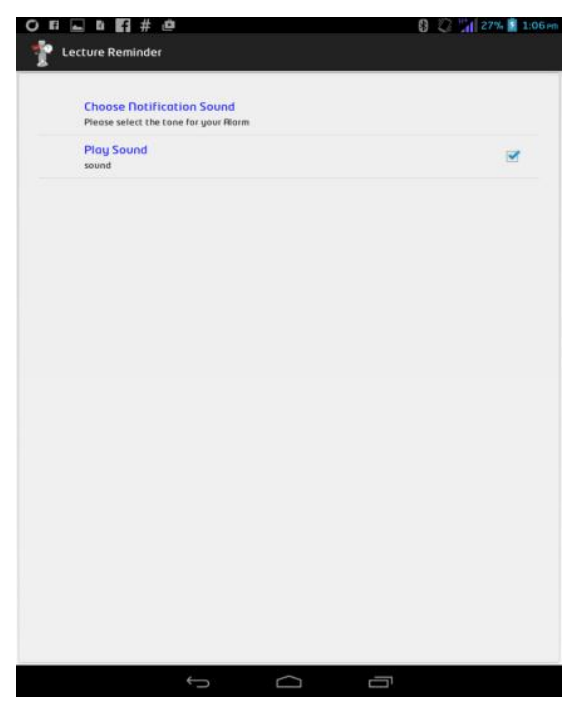

Fig.10. Page settings

It is also possible to delete schedules. Deleting of schedules option was designed with the application in case there is any error in the lecture time that has been saved. When you view the schedules, you can mark the check box and click on the delete icon at the top right corner of the "view all schedule" page. The screenshot below shows CSC 415 being checked and about to be deleted from the schedules

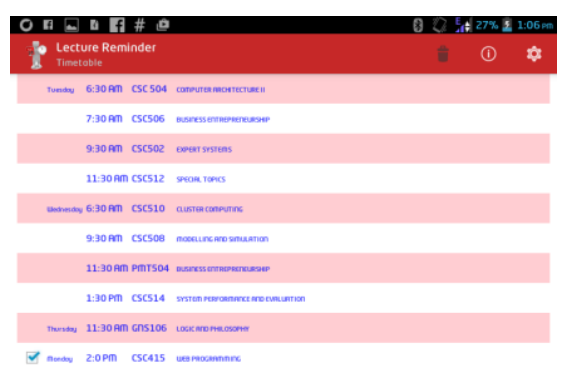

Fig.11. Deleting option 


\section{Conclusions}

This project implements lectures time table reminder system on Android platform. The design and implementation of the project was successful. Users/students can benefit from this project by downloading the application on their phones, installing it, launching it with internet connection is needed only at the first use of the application in order to download the pre-loaded lectures time table. And students are allowed to set their respective outstanding course(s) if at all that exists.

\section{Recommendation}

After the full implementation of the system using 500 level, Computer Science Department as the case study, It is therefore recommended that the application can be adopted/adapted by all other departments of the Federal University of Technology, Akure and all other higher institutions around the world so as to reduce the rate at which students forget the time of their various lectures.

\section{References}

[1] Aman Singhal, 2010. Place Me: Location Based Mobile App for Android Platform. The University of Texas, Austin.

[2] Ashok Kumar Naik, 2013. Developing a Location Based Reminder Application on Android Platform. Department of Electronics and Communication Engineering National Institute of Technology Rourkela.

[3] Devale P.R. and Pawar V.R., 2009. Time and Location Based Reminder System. Nauonal level paper presentation Excelsior '09 at SeOE,Pune.

[4] Diana Wills, "Today's requirements of mobile application development in the world”, May 04, 2012.

[5] Divya Dutta, Kuldeep Kumar, Rachit Singhal, Taruna Goswami, 2012. A major project synopsis On Event scheduler and reminder in android. Department of Computer Science and Engineering National Institute of Technology, Hamirpur (H.P.).

[6] Dragan Perakovic, Vladimir Remenar, Sinisa Husnjak, 2012. Reminder Based on the User's Location

[7] D. Rusling, The Linux Kernel. Bnited Kingdom,1996:[Online]"http://tldp.org/LDP/tlk/tlk.html"

[8] Google Inc. (2007, Nov.) Android API Reference.Google Inc. (2010, Nov.) Android Developers: http://developer.android.com/guide/developing/tools/adb.html

[9] G. Inc. (2010, Nov.) Android Developer Guide. http://developer.android.com/guide/basics/what-isandroid.html

[10] http://en.m.wikipedia.org/wiki/Android_(operating_system).http://developer.android.com/guide/compone nts/index.html/: Android Components.http://stack

[11] H. Oinas-Kukkonen, V. Kurkela, and I. Oulu, "Developing Successful Mobile Application", 2003, p. 5.

[12] Kinjal Modi, Unnati Chauhan, Jaimini Rana, Chandni Patel, Avani Rana, Vaishali Patel, 2013. Greeting reminder application based android International Journal of Innovative Research in Computer and Communication Engineering (Vol. 1, Issue 2, April 2013).

[13] Marko Gargenta , "Learning Android", Oreilly publication

[14] Pro Android, 3rd ed., Springer-Verlag New York, NY, 2009, pp. 69-132.

[15] Yazriwati and Nik, 2006. Study of techniques of class schedule/timetable Retrieval via SMS for Students' convenience research vote no.75109. 


\section{Authors' Profiles}

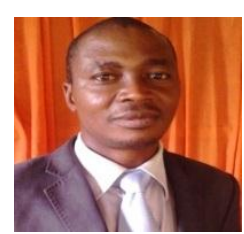

Ayeni Olaniyi: lecturer in the department of computer science of The Federal University of Technology, Akure with interest in computer vision, computer security and image processing.

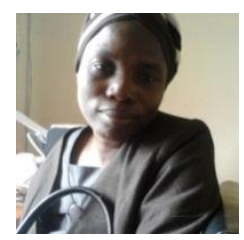

Dada Olabisi: lecturer in the department of computer science, Kwara state Polytechnic, Ilorin, Kwara-State majoring in computer security.

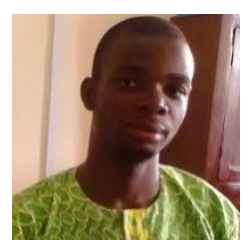

Talabi Olanrewaju: graduate of computer science department of The Federal University of Technology, Akure. Nigeria

How to cite this paper: Ayeni Olaniyi Abiodun, Dada Olabisi, Talabi Olanrewaju,"Lecture Time Table Reminder System on Android Platform (Case Study: Final Year Students, Computer Science Department)", International Journal of Wireless and Microwave Technologies(IJWMT), Vol.7, No.1, pp.13-23, 2017.DOI: 10.5815/ijwmt.2017.01.02 